American Journal of Pharmaceutical Education 2016; 80 (7) Article 119.

\title{
RESEARCH
}

\section{Relationship between Student Pharmacist Decision Making Preferences and Experiential Learning}

\author{
Charlene R. Williams, PharmD, ${ }^{\mathrm{a}}$ Jacqueline E. McLaughlin, PhD, MS, ${ }^{\mathrm{b}}$ Wendy C. Cox, PharmD, \\ Greene Shepherd, PharmD ${ }^{\mathrm{a}}$ \\ ${ }^{a}$ University of North Carolina Eshelman School of Pharmacy, Asheville Campus, Asheville, North Carolina \\ ${ }^{\mathrm{b}}$ University of North Carolina Eshelman School of Pharmacy, Chapel Hill, North Carolina \\ Submitted July 9, 2015; accepted October 5, 2015; published September 25, 2016.
}

\begin{abstract}
Objective. To determine if student pharmacists' preferences towards experiential and rational thinking are associated with performance on advanced pharmacy practice experiences (APPEs) and whether thinking style preference changes following APPEs.

Methods. The Rational Experiential Inventory (REI), a validated survey of thinking style, was administered to student pharmacists before starting APPEs and re-administered after completing APPEs. APPE grades were compared to initial REI scores.

Results. Rational Experiential Inventory scores remained consistent before and after APPEs. Overall, APPE grades were independent of REI scores. In a regression model, the REI experiential score was a significant negative predictor of hospital APPE grades.

Conclusion. These findings suggest that overall APPE performance is independent of decision-making preference, and decision-making style does not change following immersion into APPEs. Instead of targeting teaching strategies towards a specific decision-making style, preceptors may use pedagogical approaches that promote sound clinical decision-making skills through critical thinking and reflection.

Keywords: decision-making, student pharmacists, rational, experiential, advanced pharmacy practice experience
\end{abstract}

\section{INTRODUCTION}

Clinical decision making is necessary for success on advanced pharmacy practice experiences (APPEs) and in the practice of pharmacy. Pharmacists work collaboratively with other health care professionals, providing medication therapy management to optimize patient outcomes in a variety of settings. ${ }^{1}$ The process of identifying and resolving medication-related problems requires sound clinical decision-making. ${ }^{2}$ As pharmacists' roles and responsibilities continue to expand as evidenced by growing collaborative and interprofessional models of care, it is imperative that student pharmacists are trained in sound clinical decision-making to prepare them for contemporary pharmacy practice. ${ }^{3-6}$ Understanding how student pharmacists make decisions and the impact decision making has on performance in experiential practice settings may inform how to teach clinical reasoning skills.

The discipline of cognitive psychology extensively explores the cognitive issues underlying the decision-making

Corresponding Author: Charlene R. Williams, UNC Eshelman School of Pharmacy, Asheville Campus, 1 University Heights, 114 Karpen Hall, CPO \#2125, Asheville NC 28804. Tel: 828-250-3906. Fax: 828-250-3842. E-mail: charlene_williams@unc.edu process. $^{7-10}$ Cognitive-experiential self-theory (CEST) proposes that people process information by two parallel interacting systems: the rational and experiential systems. The two systems operate continuously, with behavior and conscious thought an outcome of the two systems' integrated interaction. ${ }^{7,8}$ The rational system has been described as analytic, slow, conscious, and obtained by cultural and formal instruction; while the experiential system is fast, unconscious, heuristic, intuitive, recognition-primed, and acquired through experience and biology. ${ }^{8,9}$ While people use both rational and experiential processes in decision making, individuals differ in which system they use predominately. ${ }^{10}$

Both rational and experiential decision-making systems have merit and are necessarily used in the practice of evidence-based medicine, which is defined as the "conscientious, explicit, and judicious use of current best evidence in making decisions about the care of individual patients." 11,12 The best evidence from systematic research is then combined with clinical expertise acquired through clinical experience in the practice of evidence-based medicine. ${ }^{11,12}$

While both decision-making systems are used in evidence-based practice, more information is needed to 


\section{American Journal of Pharmaceutical Education 2016; 80 (7) Article 119.}

provide insight into whether one style of thinking is associated with better performance than the other. A hypothesis of CEST is that the rational scale is more positively associated with measures of intellectual performance such as grade point average (GPA), ${ }^{7}$ whereas constructive thinking (a measure of experiential intelligence) is a stronger predictor of practical performance. ${ }^{7,13}$ In their study examining decision-making preferences of physicians, Sladek et al found that physicians who preferred rational processing identified their practice as more consistent with treatment guidelines, while a higher preference for the experiential system was correlated with behaviors inconsistent with guidelines. ${ }^{14}$ The authors concluded that preference for experiential processing may affect practice to a greater extent, which is consistent with CEST theory that most behavior is influenced by the experiential mode. ${ }^{14}$ Psychology literature suggests that the majority of faults in decision-making occur in the experiential mode. ${ }^{15}$ The short cuts or rules used in experiential processing are useful in practice, but can lead to systematic errors such as not identifying clinical problems when they do not resemble the usual pattern of presentation. 8,16

The application of research for clinical decisionmaking in health care is limited but growing. Recently the need for more research about clinical decision-making was recognized by the Association of American Medical Colleges. ${ }^{17}$ Previous work examining decision-making styles found that third-year student pharmacists favored rational decision-making over experiential decisionmaking. ${ }^{18}$ This finding was similar to published studies in other health professions that include emergency physicians; a group of general physicians, cardiologists, medical residents, and interns; and paramedics. ${ }^{14,19,20}$

Cognitive-experiential self-theory posits that decision-making preference, like personality traits, is stable over time, but to date this has not been assessed in health care professionals or health care professions students who use clinical decision making in their practice settings. ${ }^{14}$ The use of one mode over the other in clinical decision making may depend on the level of experience of the clinician and the complexity or rarity of the presenting problem. ${ }^{21}$ The experiential or intuitive system may be used more as it becomes refined with experience and pattern recognition, while the rational or analytical system may be employed in rare or uncertain cases or by novices. ${ }^{22}$

The purpose of this study was to determine if decisionmaking preference changes as students gain more clinical experience with APPEs and if a particular decision-making style can be associated with success in APPEs. The majority of the experiential learning curriculum occurs during the fourth year of the doctor of pharmacy (PharmD) program and is a suitable time to evaluate the relationship between experiential learning and decision-making preference.

\section{METHODS}

One hundred fifty students enrolled in the third year of a professional PharmD program were invited to participate in this study. Informed consent was obtained from all participants. No incentives were provided. The study was approved by the university's institutional review board. Demographic data collected included age, gender, race/ethnicity, and prior degree completion. Grades and demographic data were obtained from a database maintained by the school. To gather data about student pharmacist decision-making styles, study participants were asked to complete an electronic survey at the end of a professional development class period consisting of the Rational Experiential Inventory (REI) in spring 2013 just prior to starting APPEs.

The REI is a validated research tool that includes 40 questions to evaluate an individual's preference for either rational (conscious, analytic) or experiential (experience-based or intuitive) decision making. ${ }^{22}$ Validation studies of the REI tool demonstrate it to be internally consistent and reliable with Cronbach $\alpha$ ranging from $0.74-0.91 .^{14,19}$ The REI consists of four subscales: rational ability (perceived level of ability to think logically and analytically); rational engagement (reliance on and enjoyment of analytical or logical thinking); experiential ability (perceived level of ability in reference to one's intuition and feelings); and experiential engagement (reliance on and enjoyment of feelings and intuition in decision making). Each subscale has 10 questions, each using a 5-point Likert scale ranging from completely false (1) to complete true (5). Overall rationality and experientiality scores are obtained by summing the respective ability and engagement subscores. ${ }^{22}$

Participants who completed the initial survey were invited to take the REI again in spring 2014 after completion of APPEs to assess the impact of experiential learning on decision-making preference by comparing REI scores before and after APPEs. The pre/postsurveys were linked via student identification numbers captured by the survey instrument. The surveys and APPE grade data were also linked via student identification number and were deidentified prior to analysis.

To assess if the impact of decision-making preference on APPE performance, each student's decisionmaking style in 2013 was compared to the numeric score for nine APPEs (0-100 scale). Correlations of grades with REI scores were made in the following categories: first APPE score, average APPE score, and first APPE score for specific practice experience types (advanced community, 


\section{American Journal of Pharmaceutical Education 2016; 80 (7) Article 119.}

advanced hospital, ambulatory care, adult acute care, clinical specialty, and elective APPE).

All quantitative data analysis was conducted in SPSS for Windows, v21 (IBM, Armonk, NY). A paired $t$ test was used to compare pre/post-APPE REI survey responses. Pearson's rho was used to examine correlations between continuous variables, including REI scores with APPE grades. Subanalyses by APPE type were also performed. Regression analysis was used to determine if the REI could predict APPE performance. Significance was established at $\alpha=0.05$. Continuous data are represented as means (standard deviations [SD]).

\section{RESULTS}

One hundred fourteen of 150 students (76\%) completed the pre-APPE REI. Seventy students were female (61.4\%), 79 were white $(69.3 \%)$, and 85 had a prior degree (74.6\%). Detailed analyses of the pre-APPE REI, including validation of the REI for this sample, are published elsewhere. ${ }^{18}$ Fifty-one of 114 students (44.7\%) completed the post-APPE REI (Table 1). In the post-APPE REI, 32 students were female $(62.7 \%), 34$ were white $(66.7 \%)$, and 34 had a prior degree (66.7\%). Students presented a preference for rational decision making in pre/post-APPE REIs. For the 51 participants who completed both surveys, there were no significant differences between pre/post-APPE REI scores (Table 2).

Mean (SD) APPE scores for first rotation month and for all APPEs were 92.3 (5.8) and 94.4 (5.2) (Table 3). Correlations with pre-APPE REI scores for first practice experience score (regardless of practice experience type) and average APPE score were weak and nonsignificant (Table 4). Subanalyses of correlations for practice experience type were also weak and nonsignificant except for advanced hospital, which was found to have a weak negative correlation with experiential ability $\left(\mathrm{r}_{\mathrm{p}}=-0.21, p=0.031\right)$ and experiential overall $\left(\mathrm{r}_{\mathrm{p}}=-0.21, p=0.030\right)$. When placed into a regression model that controlled for rational score, age, gender, and prior degree yes/no, the experiential score was a significant predictor of advanced hospital APPE score $(p=0.049)$ with an unstandardized B of -1.84 . For the regression model, $\mathrm{r}^{2}$ was 0.072 .

\section{DISCUSSION}

This study assessed the relationship between experiential learning and decision-making preference. This is one of the first studies examining the REI and experiential learning performance, as well as the change in decisionmaking preference over time. The lack of relationship between decision-making preference and APPE performance limits the utility of the REI for predicting success on APPEs. The absence of a change in decision-making
Table 1. Demographics of Students Completing the REI PreAPPE and Post-APPE

\begin{tabular}{lcr}
\hline & $\begin{array}{c}\text { Pre-APPE } \\
\text { N=114 (\%) }\end{array}$ & $\begin{array}{r}\text { Post-APPE } \\
\text { N=51 (\%) }\end{array}$ \\
\cline { 2 - 3 } & \multicolumn{2}{c}{$\mathbf{n}(\mathbf{\%})$} \\
\hline Gender & $19(37.3)$ \\
Male & $44(38.6)$ & $32(62.7)$ \\
Female & $70(61.4)$ & \\
Ethnicity & $79(69.3)$ & $34(66.7)$ \\
White & $27(23.7)$ & $14(27.4)$ \\
Other & $8(7)$ & $3(5.9)$ \\
Not reported & $27(23.7)$ & $15(29.4)$ \\
Age (years) & $62(54.4)$ & $28(54.9)$ \\
20-24 & $25(21.9)$ & $8(15.7)$ \\
25-29 & & \\
$\geq 30$ & $85(74.6)$ & $34(66.7)$ \\
Prepharmacy achievement & $29(25.4)$ & $17(33.3)$ \\
Prior degree & \\
No prior degree & \\
aPre-APPE data originally published elsewhere & \\
APPE=Advanced Pharmacy Practice Experience \\
REI=Rational Experiential Inventory
\end{tabular}

preference after immersion in APPEs suggests that evaluating the REI for short-term changes may not be useful.

The finding that experiential learning did not significantly impact decision-making preference aligns with CEST theory, which suggests that decision-making preference does not change over time. ${ }^{15}$ However, use of one mode over the other in clinical decision making may depend on the level of the experience of the clinician and the situation. $^{21}$ Theory describing how clinical expertise develops suggests that reliance on experiential processing for clinical decision making increases over time as experience facilitates pattern recognition (ie, similar problems are readily recognized because of the pattern created by past experiences). ${ }^{23}$ The Dreyfus model of skills acquisition, while not without criticism for simplifying the complex process of learning, is used in medicine to describe

Table 2. Comparison of Mean Responses to the Pre-APPE REI and Post-APPE REI Scores, $\mathrm{N}=51$

\begin{tabular}{lccc}
\hline Construct & $\begin{array}{c}\text { Premean } \\
\text { (SD) }\end{array}$ & $\begin{array}{c}\text { Postmean } \\
\text { (SD) }\end{array}$ & $\boldsymbol{p}$ value \\
\hline Rational Ability & $3.96(0.50)$ & $3.98(0.44)$ & 0.871 \\
Rational Engagement & $3.77(0.58)$ & $3.71(0.58)$ & 0.643 \\
Rational Overall & $3.87(0.48)$ & $3.85(0.46)$ & 0.835 \\
Experiential Ability & $3.39(0.41)$ & $3.39(0.56)$ & 0.981 \\
Experiential Engagement & $3.21(0.49)$ & $3.22(0.58)$ & 0.914 \\
Experiential Overall & $3.30(0.39)$ & $3.31(0.53)$ & 0.938 \\
\hline
\end{tabular}

$\mathrm{APPE}=$ advanced pharmacy practice experience $\mathrm{REI}=$ Rational Experiential Inventory 


\section{American Journal of Pharmaceutical Education 2016; 80 (7) Article 119.}

Table 3. First APPE Month Scores and All APPE Scores

\begin{tabular}{lclc}
\hline First APPE Scores, & $\mathbf{N}=\mathbf{1 1 3}^{\mathbf{a}}$ & All APPE Scores, & $\mathbf{N}=\mathbf{7 4 2}^{\mathbf{b}}$ \\
\hline Mean & 92.3 & Mean & 93.7 \\
Standard Error & 0.5 & Standard Error & 0.19 \\
Median & 93.5 & Median & 94.4 \\
Mode & 100 & Mode & 100 \\
Standard Deviation & 5.80 & Standard Deviation & 5.16 \\
Range & 26.2 & Range & 29.6 \\
Min & 73.6 & Minimum & 70.4 \\
Max & 100 & Maximum & 100 \\
\hline
\end{tabular}

${ }^{\mathrm{a}} \mathrm{N}<114$ because of either delay in completion of APPE or nonreport of grade at time of analysis

${ }^{b} \mathrm{~N}<1026$ because of either delay in completion of APPE or nonreport of grade at time of analysis

$\mathrm{APPE}=$ advanced pharmacy practice experience

how clinical expertise develops. ${ }^{23}$ This model describes the gradual transition from reliance on rules and analytical processes to intuitive models of reasoning that are based on tacit understanding. ${ }^{23}$ Expertise may take up to 10 years to develop, as with expert musicians. ${ }^{24}$ Our findings suggest that decision-making preference is unchanged with acute learning, and more studies are needed to evaluate the long-term effects of clinical experience on pharmacist decision making. It may be useful to evaluate the REI later in one's career, as nine months may be too short of a time for decision-making style to change.

The absence of a relationship between decisionmaking preference and average APPE performance suggests that pedagogical strategies should engage and develop

Table 4. Correlations with Pre-REI Scores (Rational, Experiential, and All Subscale Scores)

\begin{tabular}{|c|c|c|}
\hline APPE & $\begin{array}{c}\text { Correlation } \\
\text { Range }\left(r_{p} \text { Range }^{a}\right)\end{array}$ & $\mathbf{N}^{\mathrm{c}}$ \\
\hline $\begin{array}{l}\text { First rotation score (regardless } \\
\text { of rotation type) }\end{array}$ & -0.16 to 0.01 & 114 \\
\hline Average rotation score & -0.06 to -0.01 & 114 \\
\hline $\begin{array}{l}\text { Advanced community (first time } \\
\text { rotation type completed) }\end{array}$ & -0.11 to 0.15 & 108 \\
\hline $\begin{array}{l}\text { Advanced hospital (first time } \\
\text { rotation type completed) }\end{array}$ & -0.21 to $0.08^{\mathrm{b}}$ & 110 \\
\hline Ambulatory care & -0.04 to 0.08 & 103 \\
\hline Adult acute care & -0.19 to 0.04 & 104 \\
\hline Clinical Specialty & -0.03 to 0.18 & 97 \\
\hline Elective & -0.11 to 0.15 & 104 \\
\hline \multicolumn{3}{|c|}{$\begin{array}{l}{ }^{\mathrm{a}} \text { All correlations not significant except advanced hospital } \\
{ }^{\mathrm{b}} \text { Correlations for experiential ability }\left(\mathrm{r}_{\mathrm{p}}=-0.21, p=0.031\right) \text { and expe- } \\
\text { riential overall }\left(\mathrm{r}_{\mathrm{p}}=-0.21, p=0.030\right) \text { weak and significant } \\
{ }^{\mathrm{c}} \mathrm{N}<114 \text { because of either delay in completion of APPE or nonreport } \\
\text { of grade at time of analysis } \\
\text { APPE = advanced pharmacy practice experience } \\
\text { REI = Rational Experiential Inventory }\end{array}$} \\
\hline
\end{tabular}

rational and experiential thinking styles. Clinical decisionmaking theorists in medicine suggest that the hallmark of a good decision maker is the ability to match the processing systems to the appropriate situation and incorporate them both in the overall decision. ${ }^{22}$ For example, diagnostic approaches in medicine that have employed combined reasoning strategies resulted in greater diagnostic accuracy. ${ }^{25}$ Further, in a study of decision-making processes of ambulatory care pharmacists, Bartels found that while their decisions generally followed the Dreyfus model of expertise, experienced pharmacists were able to individualize patient care using objective and contextual information and not solely rely on pattern recognition. ${ }^{26}$ Understanding the process of decision making shifts the focus from which decision-making process is preferred, to how to approach decision making to reduce the risk of errors. ${ }^{15}$ Most diagnostic errors reflect flaws in clinical reasoning instead of a lack of knowledge. ${ }^{27-29}$ Training in formal decision making, critical thinking, problem solving, and understanding biases that affect decisions as well as one's own decision-making preferences is suggested in medicine to improve clinical reasoning skills. ${ }^{8,30}$ Accreditation standards for the PharmD program also endorse teaching and learning methods that foster development of criticalthinking and problem-solving skills. ${ }^{31}$ While it may take years of experience to fully develop these skills, preceptors can nurture their development by encouraging learners to evaluate factors and processes involved in clinical decision making.

There was a weak negative relationship between advanced hospital APPE scores and experiential decision making. The negative relationship between advanced hospital APPE scores and experiential decision-making preference suggests that highly intuitive students may receive lower scores on advanced hospital experiences compared to students who prefer analytical decision making. This result is unexpected as other APPEs, such as clinical specialty or adult acute care that may require a high level of analytical processing as a novice in the assessment and application of evidence-based medicine, did not show similar results. Advanced hospital practice experiences also have a medication distribution component, as do advanced community practice experiences, which did not show similar results. The standards and policies related to medication use processes that health systems employ could possibly align better with rational or analytical thinking. ${ }^{32}$ This warrants additional study given that the correlation was weak and the APPE scores were high.

This study has limitations which may limit the generalizability to other populations. The study population came from one school of pharmacy. Future research 


\section{American Journal of Pharmaceutical Education 2016; 80 (7) Article 119.}

should include a larger number of schools and students. Another limitation is that a significant portion of the students who completed the first REI did not complete the second one. Finally, the preponderance of high APPE scores, which may suggest grade inflation, along with variability in preceptor grading, could limit the ability to detect a relationship between decision-making preference and APPE performance. Future directions may include determining the decision-making preferences of pharmacists along a continuum of experience as their dependence on the rational processing mode may decrease over time. Other future research could examine the relationship between decision-making preference and the factors involved in individual clinical decisions. Additionally, interventions that promote critical thinking and reflection should be assessed for impact on APPE performance.

\section{CONCLUSION}

Student pharmacists' decision-making preference was not strongly associated with APPE performance in this study, and decision-making preference did not appear to change following immersion in advanced experiential learning. Pedagogical methods that promote sound clinical decision-making skills through critical thinking and reflection are recommended, regardless of decisionmaking preference. The relationship between advanced hospital APPE scores and decision-making style warrants further study. Future research directions include determining the decision-making preference of expert pharmacists and evaluating whether reflective practice changes the quality of pharmacist decision making.

\section{ACKNOWLEDGMENTS}

The authors would like to thank Andrew Clapper for his assistance with survey administration. Manuscript development support was provided by the National Center for Advancing Translational Sciences and a National Institutes of Health grant award. The content is solely the responsibility of the authors and does not necessarily represent the official views of the NIH.

\section{REFERENCES}

1. American College of Clinical Pharmacy. Standards of practice for clinical pharmacists. Pharmacotherapy. 2014;34(8):794-797.

2. Joint Commission of Pharmacy Practitioners. Pharmacists' patient care process. American Pharmacists Association. https://www. pharmacist.com/sites/default/files/files/PatientCareProcess.pdf. Published May 29, 2014. Accessed September 12, 2016.

3. Nigro SC, Garwood CL, Berlie H, et al. Clinical pharmacists as key members of the patient-centered medical home: an opinion statement of the ambulatory care practice and research network. Pharmacotherapy. 2014;34(1):96-108.
4. Schnur ES, Adams AJ, Kelpser DG, Doucette WR, Soctt DM. PCMHs, ACOS, and medication management: lessons learned from early research partnerships. J Manag Care Pharm. 2014;20(2):201-205. 5. Weaver K. Collaborative practice agreements vary among the states. American Pharmacists Association. http://www.pharmacist. com/collaborative-practice-agreements-vary-among-states. 2013. Accessed March 13, 2014.

6. Yap D. Kansas collaborative practice law becomes effective July 1, 2014. American Pharmacists Association. http://www.pharmacist. com/kansas-collaborative-practice-law-becomes-effective-july-1-2014. 2014. Accessed November 1, 2014.

7. Epstein S, Pacini R, Denes-Raj V, Heier H. Individual differences in intuitive-experiential and analytical-rational thinking styles. J Pers Soc Psychol. 1996;71(2):390-405.

8. Sladek RM, Phillips PA, Bond MJ. Implementation science: a role for parallel dual processing models of reasoning? Implement Sci. 2006;1(12):1-8.

9. Stanovich KE, West RF. Individual differences in reasoning: implications for the rationality debate? Behav Brain Sci. 2000;23 (5):645-726.

10. Witteman C, van den Bercken J, Claes L, Godoy A. Assessing rational and intuitive thinking styles. Eur J of Psychological Assess. 2009;25(1):39-47.

11. Sackett DL, Rosenberg WM, Gray JA, Haynes RB, Richardson WS. Evidence based medicine: what it is and what it isn't. $B M J$. 1996;312(7023):71-72.

12. Ashby D, Smith AF. Evidence-based medicine as Bayesian decision-making. Statist Med. 2000;19(23):3291-3305.

13. Epstein S. Cognitive-experiential self-theory of personality. In: Millon T, Leder MJ, eds. Handbook of Psychology, Volume 5: Personality and Social Psychology. Hoboken NJ: Wiley \& Sons; 2003:159-184.

14. Sladek RM, Bond MJ, Huynh LT, Chew DPB, Phillips PA. Thinking styles and doctors' knowledge and behaviors relating to acute coronary syndromes guidelines. Implement Sci. 2008;3(23):1-8. 15. Croskerry P, Petrie DA, Reilly JB, Tait G. Deciding about fast and slow decisions. Acad Med. 2014;89(2):197-200.

16. Kahneman D. A perspective on judgment and choice: mapping bounded rationality. Am Psychol. 2003;58(9):697-720.

17. Croskerry P, Tait G. Clinical decision making: the need for meaningful research. Acad Med. 2013;88(2):149-150.

18. McLaughlin JE, Cox WC, Williams CR, Shepherd G. Rational and experiential decision-making of third-year student pharmacists. Am J Pharm Educ. 2014;78(6): Article 120.

19. Calder LA, Forster AJ, Stiell IG, et al. Experiential and rational decision making: a survey to determine how emergency physicians make clinical decisions. Emerg Med. 2012;29(10):811-816.

20. Jensen JL, Calder LA, Walker M, et al. Experiential and rational clinical decision making: a survey to determine decision-making styles of paramedics. CJEM. 2013;15(S1): S1.

21. Croskerry P. A universal mode of diagnostic reasoning. Acad Med. 2009;84(8):1022-1028.

22. Pacini R, Epstein S. The relation of rational and experiential information processing styles to personality, basic beliefs, and the ratio-bias phenomenon. J Pers Soc Psychol. 1999;76(6):972-987. 23. Pena, A. The Dreyfus model of clinical problem-solving skills acquisition: a critical perspective. Med Educ Online. 2010;15(1):4840DOI:10.3402/meo.v15i0.4846.

24. Ericsson, KA. Deliberate practice and the acquisition and maintenance of expert performance in medicine and related domains. Acad Med. 2004;79(10 Suppl):S70-S81. 


\section{American Journal of Pharmaceutical Education 2016; 80 (7) Article 119.}

25. Ark TK, Brooks LR, Eva LW. The benefits of flexibility: the pedagogical value of instructions to adopt multifaceted diagnostic reasoning strategies. Med Educ. 2007;41(3):281-287.

26. Bartels CE. Analysis of experienced pharmacist clinical decision-making for drug therapy management in the ambulatory care setting [dissertation]. Minneapolis, MN: University of Minnesota; 2013.

27. Sandhu H, Carpenter C, Freeman K, Nabors SG, Olson A. Clinical decision making: opening the black box of cognitive reasoning. Ann Emerg Med. 2006;48(6):713-719.

28. Graber ML, Franklin N, Gordon R. Diagnostic error in internal medicine. Arch Intern Med. 2005;165(13):1493-1499.
29. Croskerry P, Singhal G, Mamede S. Cognitive debiasing 1: origins of bias and theory of debiasing. BMJ Qual Saf. 2013;22(Suppl 2):ii58-ii64. 30. Crokskerry P, Norman G. Overconfidence in clinical decision making. Am J Med. 2008;121(5 Suppl):S24-S29.

31. Accreditation Council for Pharmacy Education. Accreditation standards and guidelines for the professional program in pharmacy leading to the doctor of pharmacy degree. https://www.acpe-accredit. org/pdf/FinalS2007Guidelines2.0.pdf. Accessed January 10, 2015. 32. Vermeulen L, Rough SS, Thielke TS, et al. Strategic approach for improving the medication-use process in health systems: the high performance pharmacy practice framework. Am J Health Syst Pharm. 2007;64(16):1699-1710. 